Supplement of Atmos. Chem. Phys. Discuss., 15, 23731-23794, 2015

http://www.atmos-chem-phys-discuss.net/15/23731/2015/

doi:10.5194/acpd-15-23731-2015-supplement

(C) Author(s) 2015. CC Attribution 3.0 License.

(c) (i)

\title{
Assessing the ammonium nitrate formation regime in the Paris megacity and its representation in the CHIMERE model
}

\section{H. Petetin et al.}

Correspondence to: H. Petetin (hervepetetin@gmail.com)

The copyright of individual parts of the supplement might differ from the CC-BY 3.0 licence. 

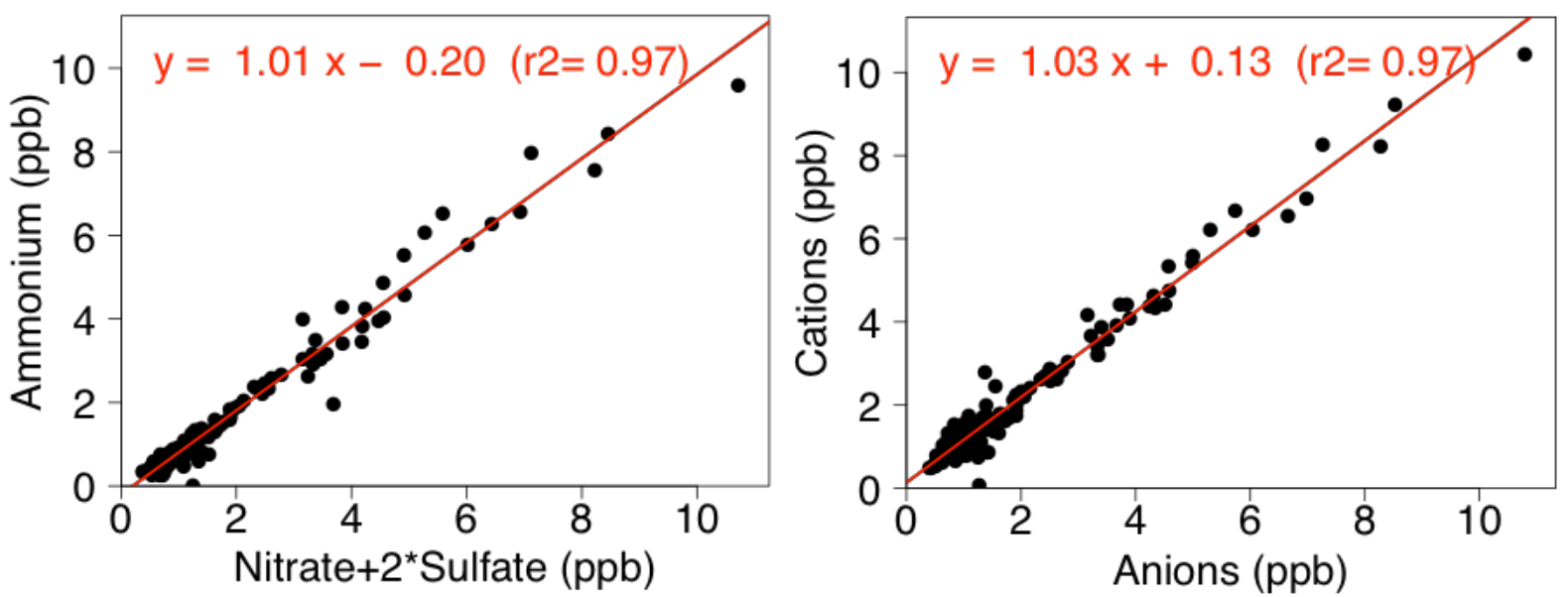

Figure S1: Ions balance in Paris (based on daily observations), considering only $\mathrm{NH}_{4}{ }^{+}$versus $\mathrm{NO}_{3}{ }^{-}$ $+2 \mathrm{SO}_{4}{ }^{2-}$ (left panel) and all available cations and anions (i.e. $\mathrm{NH}_{4}{ }^{+}+\mathrm{K}^{+}+2 \mathrm{Ca}^{2+}+\mathrm{Na}^{+}+2 \mathrm{Mg}^{2+}$ versus

$\left.7 \quad \mathrm{NO}_{3}{ }^{-}+2 \mathrm{SO}_{4}{ }^{2-}+\mathrm{Cl}-\right)$ (right panel).

\section{S.2 Evaluation of the meteorology}

9

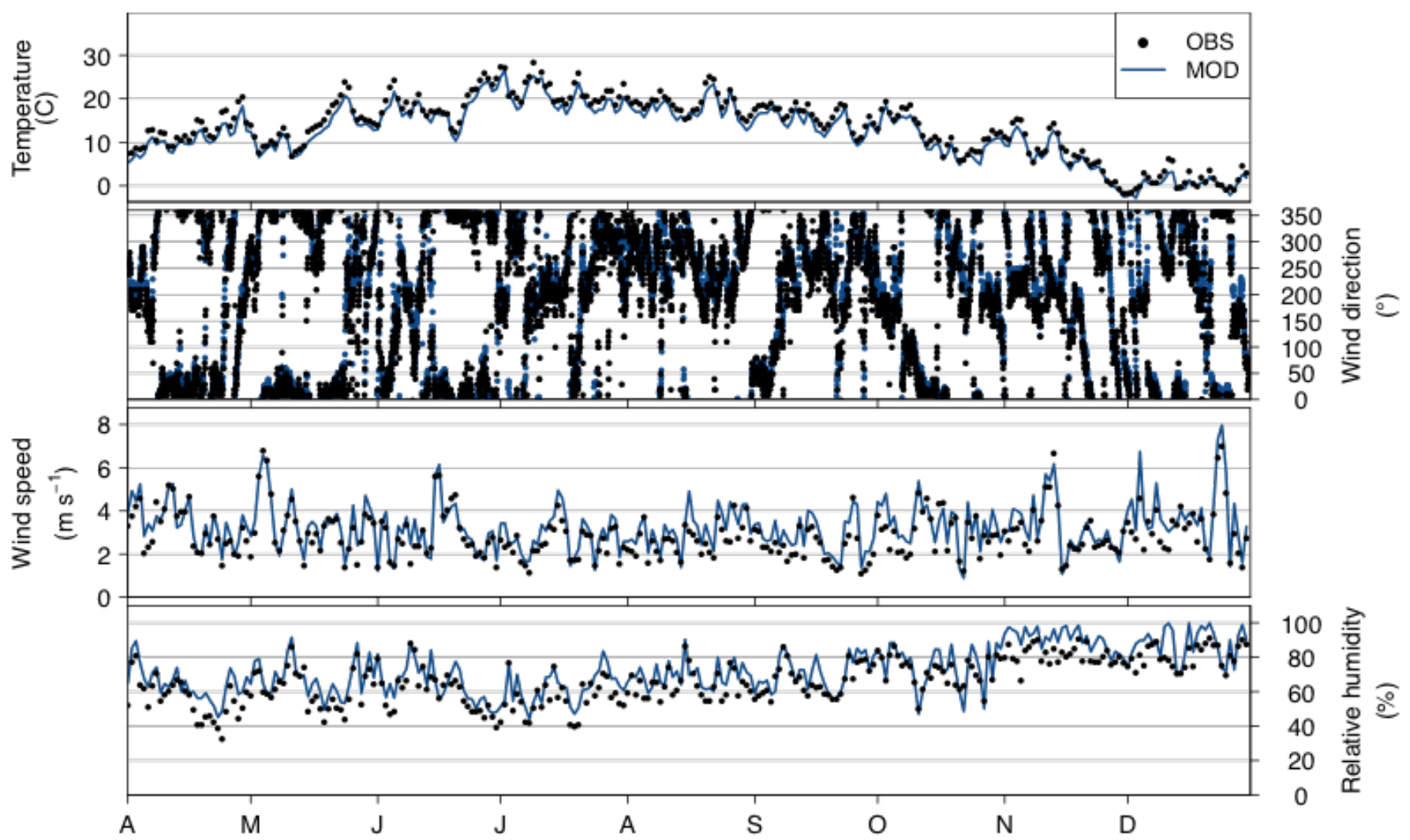

Figure S2: Measured and simulated daily temperature, hourly wind direction, daily wind speed and relative humidity at the MONTSOURIS site in Paris. 


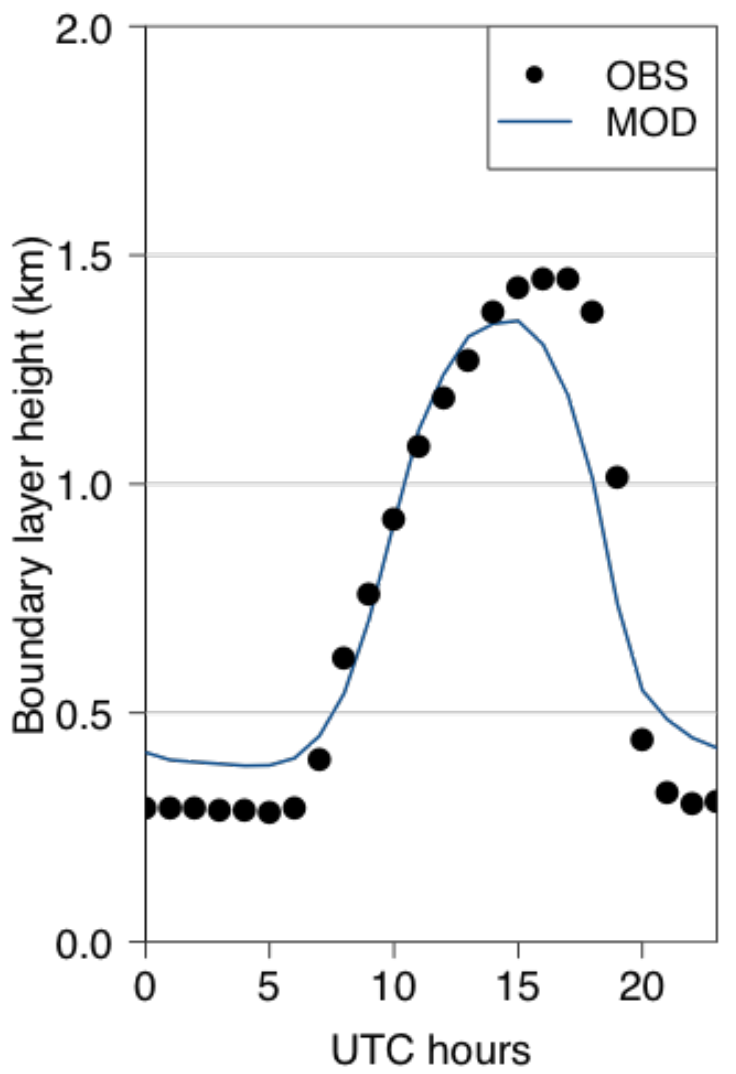

2 Figure S3: Measured and simulated boundary layer height $(\mathrm{BLH})$ diurnal profile (average over the 3 whole studied period) at the SIRTA site, measurements being derived from aerosol lidar 4 observations.

5

6

7 Table S1: Statistical results on the meteorological parameters at the MONTSOURIS station (and at 8 SIRTA site for the boundary layer height).

\begin{tabular}{lcccccc}
\hline Parameter & MB & $\begin{array}{c}\text { NMB } \\
(\%)\end{array}$ & RMSE & $\begin{array}{c}\text { NRMSE } \\
(\%)\end{array}$ & R & $\begin{array}{c}\text { N } \\
(\%)\end{array}$ \\
\hline Temperature $\left({ }^{\circ} \mathrm{C}\right)$ & -1.6 & - & 2.3 & - & 0.98 & 99 \\
Wind speed $\left(\mathrm{m} \mathrm{s}^{-1}\right)$ & +0.4 & +13 & 0.9 & 32 & 0.80 & 99 \\
Relative humidity $(\%)$ & +5.9 & +9 & 11.0 & 17 & 0.80 & 99 \\
Boundary layer height $(\mathrm{m})$ & +84 & +11 & 384 & 52 & 0.80 & 58 \\
\hline
\end{tabular}

9

\section{S.3 $\mathrm{NH}_{3}$ emissions in the Paris region}

11 According to the TNO-MP inventory (see Table S2), the main $\mathrm{NH}_{3}$ emission sources in the Paris

12 region are the agriculture (SNAP 10,67\%), the combustion in manufacturing industry (SNAP 3, $1320 \%$ ), followed by production processes (SNAP 4, 8\%) and non-industrial combustion plants 14 (SNAP 2, 4\%). Compared to the repartition of emissions at the national scale, the main 
1 discrepancies are found in SNAP 10 (that represent 96\% of French $\mathrm{NH}_{3}$ emissions) and SNAP 3

2 (whose emissions are essentially concentrated in the Paris region). Despite the much higher

3 contribution of emission sources other than agricultural in the Paris region (33 against 4\%), the

4 local formation of ammonia in Paris remains very low, which underlines again the importance of

5 SNAP 10 emissions outside the Paris region.

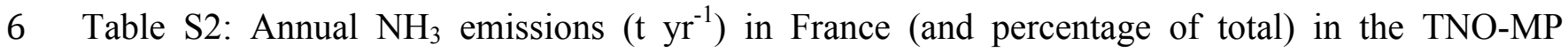
7 inventory.

\begin{tabular}{lll}
\hline SNAP* sector and description & France & Paris region \\
\hline 1. Combustion in energy and transformation industries & $49(<1 \%)$ & $0(0 \%)$ \\
2. Non-industrial combustion plants & $240(<1 \%)$ & $194(4 \%)$ \\
3. Combustion in manufacturing industry & $1032(<1 \%)$ & $1012(20 \%)$ \\
4. Production processes & $3034(<1 \%)$ & $416(8 \%)$ \\
5. Extraction/distribution of fossil fuels/geothermal energy & $6(<1 \%)$ & $0(0 \%)$ \\
6. Solvent use and other product use & $15(<1 \%)$ & $0.05(<1 \%)$ \\
7. Road transport & $13617(2 \%)$ & $0(0 \%)$ \\
8. Other mobile sources and machinery & $6(<1 \%)$ & $0(0 \%)$ \\
9. Waste treatment and disposal & $10315(1 \%)$ & $11(<1 \%)$ \\
10. Agriculture & $717177(96 \%)$ & $3361(67 \%)$ \\
\hline Total & $745489(100 \%)$ & $4994(100 \%)$ \\
\hline
\end{tabular}

* SNAP: Selected Nomenclature Air Pollution.

\section{S.4 Other supplementary figures}

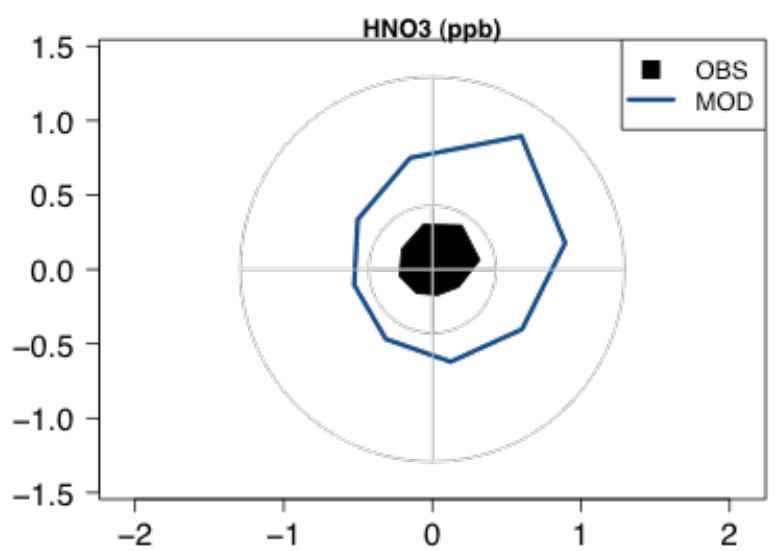

11 Figure S4 : Measured and simulated pollution rose of $\mathrm{HNO}_{3}$ in Paris. $\mathrm{HNO}_{3}$ concentrations are 12 measured at LHVP, wind direction is measured at the MONTSOURIS site (two kilometers from 13 LHVP). 

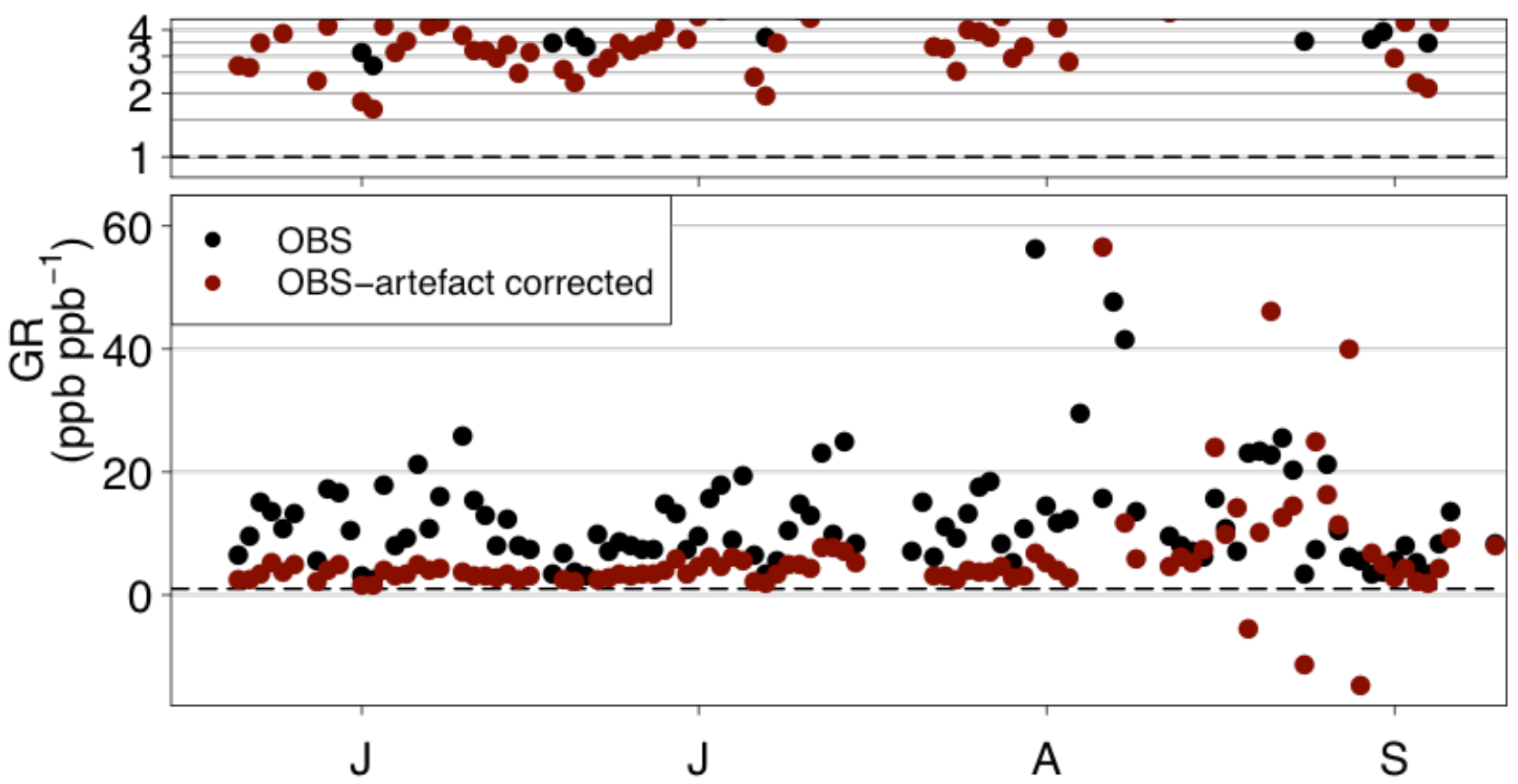

2 Figure S5: Experimentally determined GR with raw concentration data (in black) and with artefact-

3 corrected ammonium and nitrate concentrations (in red) (see text in Sect. 4.4.2 for explanations) in 4 the low panel. Zoom with logarithmic scale in the top panel.

5
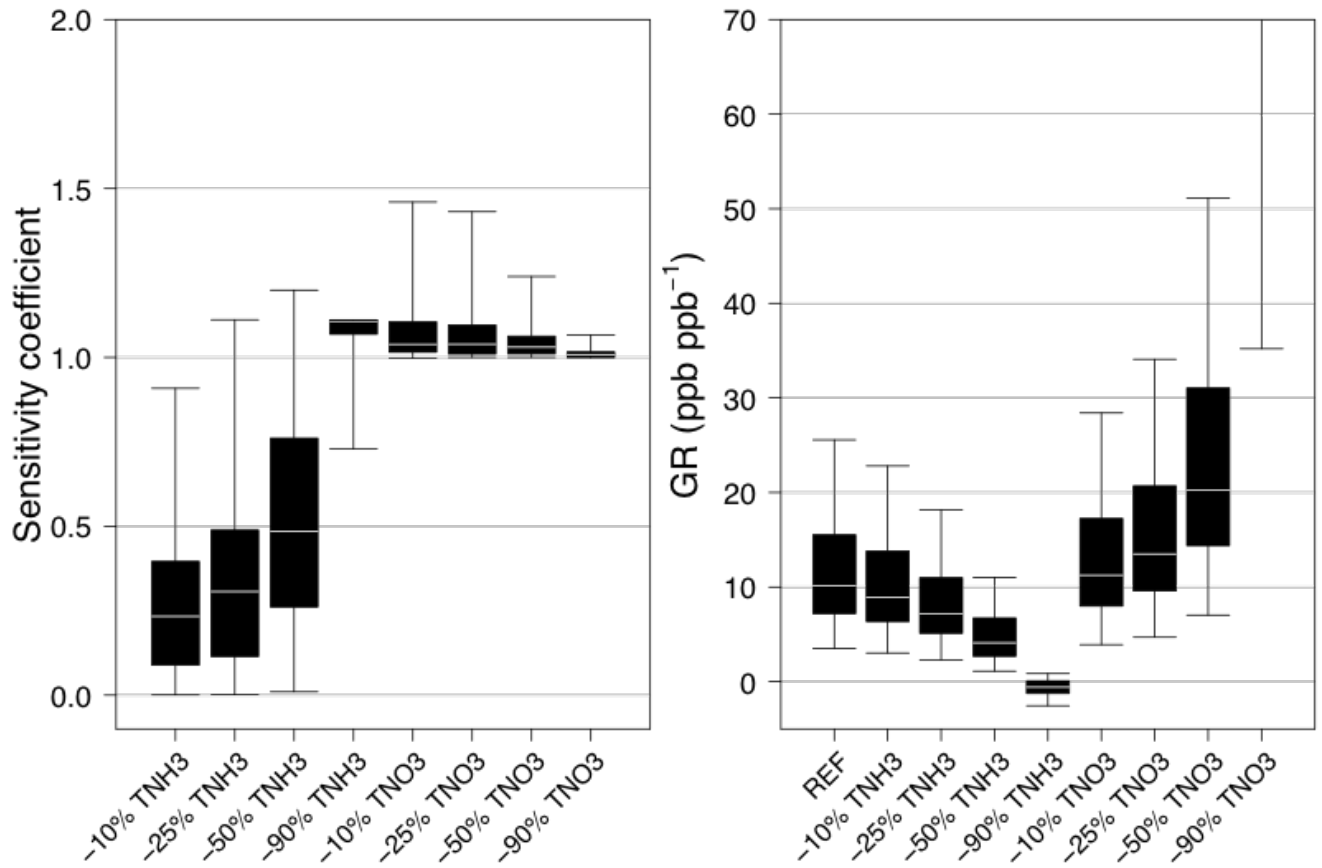

Figure S6: Sensitivity coefficient of aerosol nitrate to different changes $(-10,-25,-50$ and $-90 \%)$ in $\mathrm{TNH}_{3}$ and $\mathrm{TNO}_{3}$ concentrations (left panel) and resulted GR (right panel) during the period from 2010 May 15 to September 10, deduced from observations with temperature decreased by $10^{\circ} \mathrm{C}$ and RH increased by 0.20 . 